\title{
Penis Allotransplantation in Beagle Dog
}

\author{
Yongbin Zhao, Weilie Hu, Lichao Zhang, Fei Guo, Wei Wang, \\ Bangqi Wang, and Changzheng Zhang \\ Department of Urology, The General Hospital of Guangzhou Military Command, No. 111, Liuhua Road, Guangzhou, \\ Guangdong 510010, China \\ Correspondence should be addressed to Weilie Hu; huwl-mr@vip.sina.com
}

Received 14 September 2015; Revised 30 November 2015; Accepted 10 December 2015

Academic Editor: Gerald Brandacher

Copyright (C) 2016 Yongbin Zhao et al. This is an open access article distributed under the Creative Commons Attribution License, which permits unrestricted use, distribution, and reproduction in any medium, provided the original work is properly cited.

\begin{abstract}
This is an original research of penis allotransplantation. The paper presents an experiment allogenic penis transplantation model in Beagles, with a focus on recovery of blood supply and changes in tissue architecture. Twenty adult Beagles were allocated to 10 pairs for penile transplantation. After operation, the skin and glans were observed. If adverse symptoms occurred, the transplanted penis was resected and pathologically examined. Frequency of urination, urinary stream, and patency level were recorded 7 days after transplantation. Cystourethrography was performed on Day 10. The transplanted penises were resected on Day 14 for pathological examination. The research showed that transplanted penises survived after allotransplantation, and the dogs regained urination ability. Penis autotransplantation in Beagles is feasible. This preliminary study shows a potential for application of this new procedure for penis transplantation in humans.
\end{abstract}

\section{Introduction}

War injury, trauma, penis tumor surgery, and congenital diseases may be associated with partial or complete penile defect, which deprives men of the ability of urination while standing and sexual activity. This condition often causes mental and psychological trauma and induces a heavy emotional and psychological burden to the patients and their families. The main treatment methods for penis defects include phalloplasty with free flaps or pedicled flaps, penis lengthening, and penis reconstruction [1-3]. Ideal treatment should achieve excellent appearance and feeling, ability to urinate while standing, and successful sexual intercourse. The first case of penis replantation has been performed in 1971 [4], and has been followed by many others. However, replantation is not always possible and reconstruction is then necessary.

Resection of the superficial suspensory ligament and about one- to two-thirds of the deep suspensory ligament may be performed to increase the length of the penis, which could increase the length by about $3.2-5.0 \mathrm{~cm}$ (mean $4.1 \mathrm{~cm}$ ) and $0.8-1.2 \mathrm{~cm}$, respectively. However, there is a high risk of injuring the deep dorsal vein, dorsal artery, and nerves.
Although this method could help patients with complete penile defect to regain the ability of standing urination, several issues remain including poor appearance of the glans penis, short penis length $(<5.0 \mathrm{~cm})$, and erectile dysfunction [5-8]. Recently, V-Y advancement flaps from the lower pubic area are being widely used in $\mathrm{V}$-Y plasty to increase the length of penis $[9,10]$. However, this approach also suffers from poor appearance of the glans penis, limited penile length, and erectile dysfunction.

Therefore, reproductive organ transplantation has been suggested as an important alternative treatment for penis defects. In a retrospective study, Lee et al. analyzed animal studies (including testicle transplantation, ovarian transplantation, and en bloc vagino-utero-ovarian transplantation) performed over the past 25 years and have proposed that allogeneic penis transplantation could be applicable in the near future if approved by ethics committees [11]. One patient in China successfully underwent penis allotransplantation in 2006, but the penis had to be resected because of psychological issues [12].

Penises from Brown-Norway rats were transplanted to adult Lewis rats (en bloc allogeneic transplantation), and 
results showed that immunosuppressors including FK506 could effectively prevent rejection in allogenic penis transplantation [13]. Transplantation of single organ including kidney, heart, liver, and lung has been widely applied, and the technologies involved are well known. Similar to limbs, the penis consists of skin, blood vessels, nerves, cavernous bodies, albuginea, and urethral mucosa, making penile transplantation a composite tissue transplantation [14], and the rejection reactions are usually more serious than in single organ transplantation $[15,16]$. Results from animal studies have shown that penis autotransplantations had a high success rate; however, allogeneic penis transplantation still remains a challenge for clinicians $[17,18]$. Penis defects do not endanger the life of the patients but cause profound psychological problems that greatly affect the patients' quality of life. Therefore, penis allotransplantation could be performed in selected cases with the appropriate immunosuppressive regimen.

The structures of the penis of Beagle dogs are very similar to the human penis [19]. In the present study, allogeneic penile transplantations using microsurgery were performed in Beagles to investigate the graft survival and the restoration of urination function, with a focus on recovery of blood supply and changes in tissue architecture. Results could provide evidence for allogeneic penile transplantation in humans.

\section{Materials and Methods}

2.1. Animals. Twenty Beagles (weight: $15-17 \mathrm{~kg}$, mean $16.8 \mathrm{~kg}$ ) were provided by Zhaoqing Kangda Experimental Animal Co., Ltd. The dogs had free access to water and food. The diameter of the dogs' penises ranged from 2.2 to $3.0 \mathrm{~cm}$ (mean $2.6 \mathrm{~cm}$ ). The 20 dogs were allocated to 10 pairs, each pair consisting of half-brothers in order to reduce immunological issues and to focus on blood supply and changes in tissue architecture. This study was approved by the ethics committee of our hospital and was performed according to animal protection rules.

2.2. Microsurgical Allogeneic Penis Transplantation. Lymphocyte toxicity test [20] had to be negative before surgery. Muscular injection of scopolamine $(0.3 \mathrm{mg})$ and phenobarbital sodium $(0.1 \mathrm{~g})$ was performed $30 \mathrm{~min}$ before surgery to decrease salivary gland secretion to help in performing tracheal intubation and maintain the respiratory tract unblocked. Heparin sodium (12,500 U) was intravenously injected to reduce the risk of embolism after surgery. Alternate muscular injection of Su-Mian-Xin II $(0.08 \mathrm{~mL} / \mathrm{kg})$ and ketamine $(5-10 \mathrm{mg} / \mathrm{kg}$ ) was performed to induce general anesthesia. Iodine and alcohol were used to disinfect the skin. A U-shaped incision was made in the pubic area after draping. The cavernous body of the penis was isolated from the root of the scrotum, while the dorsal vessels and nerves were kept intact. The penis was resected at about $3 \mathrm{~cm}$ from the penile head, and a rubber band was used to block the blood flow. The resected penis was preserved in tissue protection fluid at $4^{\circ} \mathrm{C}$ for $30 \mathrm{~min}$ to remove the residual blood in the resected penis.
The bilateral dorsal veins and arteries and accompanying nerves were carefully isolated and protected under the assistance of a surgical microscope (magnification: 10x). About $2 \mathrm{~cm}$ of the vessels and nerves were isolated. Then, a clamp was used to block the vessels, and the tunica intima was rinsed using heparin sodium solution to prevent thrombosis. The residual cavernous body was ligated with a rubber band, and the dorsal vessels and nerves were isolated for about $2 \mathrm{~cm}$. A custom-made $12 \mathrm{~F}$ silica gel induct catheter was inserted through the external urethral orifice into the bladder. Absorbable suture (4-0) was used to suture the cavernous body of urethra and albuginea of cavernous body of penis to restore the continuity of the penis and urethral canal. Continuous suture with two fixed points was performed to anastomose the deep dorsal vein of the penis using 9-0 damage-free vascular suture. Suture of the dorsal artery of the penis and accompanying nerves was made using 11-0 damagefree vascular suture. The rubber band was then loosened to identify any blood leakage of the vascular anastomosis and to observe the arterial pulse and vein filling. Size- 4 thread was used to suture the subcutaneous tissue and size-7 thread was used to suture the penile skin. The incisions were covered by sterile gauzes and bound with elastic bandages.

2.3. Treatments and Observation. Combined immune induction was performed using preoperative FK506 (2 mg) and MMF (250 mg). Methylprednisolone (500 mg) and pantoprazole ( $80 \mathrm{mg}$ ) were used intraoperatively. Intravenous dripping of dexamethasone $(7.5 \mathrm{mg} / \mathrm{kg})$ was performed for 3 days (once/day) after surgery and then switched to $0.2 \mathrm{mg} / \mathrm{kg} / \mathrm{d}$ of muscular injection for immune induction therapy. Maintenance immunosuppressive therapy using FK506 $(1 \mathrm{mg} / \mathrm{kg} / \mathrm{d}$, intragastric administration) and MMF $(20 \mathrm{mg} / \mathrm{kg} / \mathrm{d}$, intravenous dripping) was also performed. Ampicillin and bicillin were administered to prevent infection. Nutritional therapy and supporting treatment were also performed.

After surgery, the skin and glans were carefully observed to identify any color change and tissue swelling. The catheter was removed on Day 7 after the operation. Frequency of urination, urinary stream, and patency level were recorded. Cystourethrography was performed on Day 10. The transplanted penis was resected on Day 14 for pathological examination. If the glans was white, if the skin was black, if there was obvious tissue swelling or necrosis, or if there was an irreversible acute rejection during the observation period, the transplanted penis was resected immediately and pathological examination was performed. After the period of observation, all dogs were returned to the animal center for use in studies needing large animals (such as orthopedics or cardiac surgery), in accordance with the terms of the ethical approval.

2.4. Morphology of the Penile Cavernous Body. Anatomical structures of the penis cavernous body of adult Beagles (including cavernous body of the penis, cavernous body of urethra, blood supply, and nerves) were carefully observed. The number of penis cavernous bodies, number of dorsal penis veins, diameters of the bilateral dorsal veins, number of 


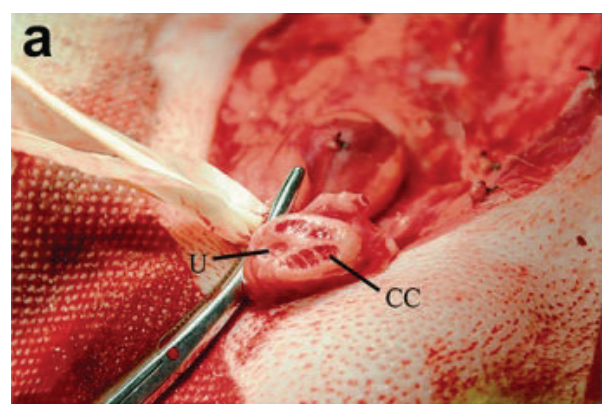

(a)

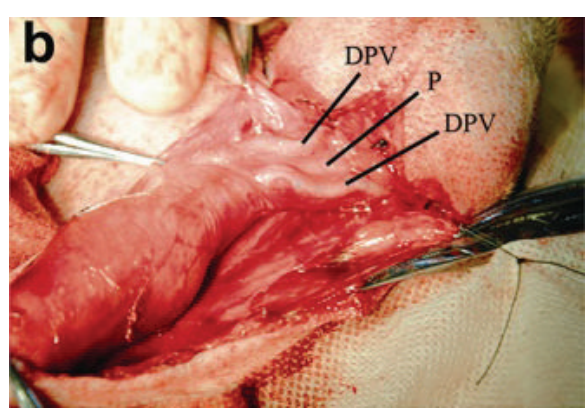

(b)

Figure 1: (a) Cross section of the cavernous bodies at the root of the penis of Beagles. (b) Dorsal penile vessels of Beagles. U: urethra; CC: corpus cavernosum; P: penis; DPV: dorsal penis vessels.

dorsal penis arteries, diameters of the bilateral dorsal arteries, and number of dorsal penis nerves were recorded.

2.5. HE Staining. Tissue sections were immersed in hematoxylin for $2 \mathrm{~min}$, rinsed with distilled water for $1 \mathrm{~min}$, immersed in eosin for $5 \mathrm{~s}$, and rinsed with distilled water for $1 \mathrm{~min}$. Section dehydration was performed using a series of alcohol concentrations ( $30 \mathrm{~s}$ for each concentration). Sections were cleared by xylene and mounted using neutral balsam.

\section{Results}

3.1. Morphology of the Penile Cavernous Body. Skin, subcutaneous tissue, albuginea, and cavernous body could be clearly seen in the cross section of the penises. Cavernous bodies were separated by dense tissues, and the bilateral penile and urethral cavernous bodies were wrapped by albuginea. Blood sinuses of the cavernous bodies were regular and clear. Dorsal arteries, veins, and accompanying nerves could be found at dorsal penis. The mean length of the glans was $7.0 \pm 1.5 \mathrm{~cm}$, and the mean diameter of the penis was $2.0 \pm 0.8 \mathrm{~cm}$. Cartilage tissues were found in the penises. Penis cavernous bodies could be found from the root of the scrotum. Symmetric dorsal veins, arteries, and accompanying nerves were found at the dorsal penis. The mean diameter was $1.16 \pm 0.11 \mathrm{~mm}$ for the left dorsal vein, $1.145 \pm 0.11 \mathrm{~mm}$ for the right dorsal vein, and $0.46 \pm 0.08 \mathrm{~mm}$ for both the left and right dorsal arteries (Figures 1(a) and 1(b), Table 1).

3.2. Survival and Morphology of the Transplanted Penises. For the 20 penis transplantations under the assistance of microsurgical techniques, the one-time success rate was 95\% (38/40) for venous anastomosis and 87.5\% (35/40) for arterial anastomosis. The mean vascular anastomosis time was $70.95 \pm 8.95 \mathrm{~min}$, mean operation time was $133.00 \pm$ $10.31 \mathrm{~min}$, and mean blood loss was $135.75 \pm 41.40 \mathrm{~mL}$ (Table 2).

Among the 20 transplanted penises, the color of the glans and skin was pale for two penises on the first day after the operation, with tissue swelling. Glans necrosis, black skin, and mild tissue swelling were observed in three penises on Day 3. Black glans and skin and dry glans were observed in another three penises on Day 5, without swelling. The
TABle 1: Anatomic features of the penis from adult Beagles.

\begin{tabular}{lc}
\hline Parameters & Value \\
\hline$n$ & 20 \\
Mean number of cavernous bodies & $3 \pm 0$ \\
Mean number of dorsal penile veins & $2 \pm 0$ \\
Mean diameter of dorsal penile veins $(\mathrm{mm})$ & \\
$\quad$ Left & $1.16 \pm 0.11$ \\
$\quad$ Right & $1.145 \pm 0.11$ \\
Mean number of dorsal penile arteries & $2 \pm 0$ \\
Mean diameter of dorsal penile arteries $(\mathrm{mm})$ & \\
$\quad$ Left & $0.46 \pm 0.08$ \\
$\quad$ Right & $0.46 \pm 0.08$ \\
Mean number of dorsal penile nerves & \\
$\quad$ Left & $1.35 \pm 0.49$ \\
$\quad$ Right & $1.30 \pm 0.47$ \\
\hline
\end{tabular}

TABLE 2: Parameters of penis transplantations.

\begin{tabular}{lc}
\hline Parameters & Value \\
\hline$n$ & 20 \\
Number of dorsal veins & 40 \\
Number of one-time successes & 38 \\
Success rate & $95 \%$ \\
Number of dorsal arteries & 40 \\
Number of one-time successes & 35 \\
Success rate & $87.5 \%$ \\
Vascular anastomosis time (min) & $70.95 \pm 8.95$ \\
Operation time (min) & $133.00 \pm 10.31$ \\
Blood loss volume $(\mathrm{mL})$ & $135.75 \pm 41.40$ \\
\hline
\end{tabular}

remaining 12 penises had a ruddy glans and mild pale penile skin, without swelling (Figure 2(a)). The incisions of these 12 penises recovered well, and the catheters were removed on Day 7. Normal urination and linear urinary stream were found (Figure 2(b)). No urethrostenosis was found by cystourethrography (Figure 2(c)).

3.3. Pathological Examination. Light microscopy examinations showed that the skin and subcutaneous tissues had 


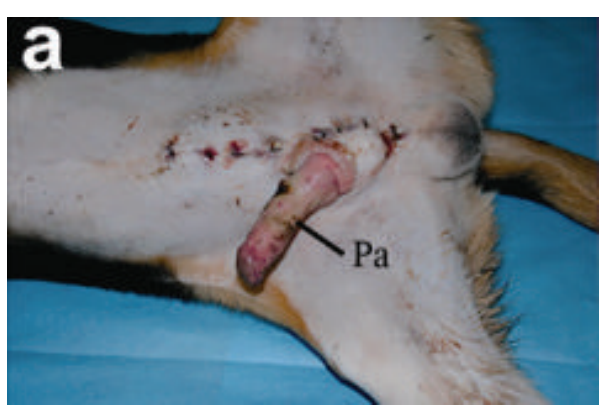

(a)

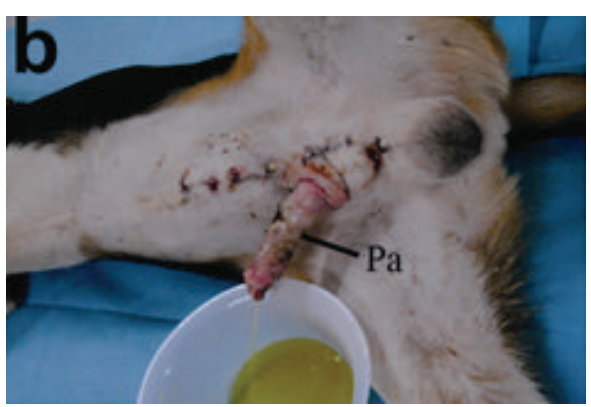

(b)

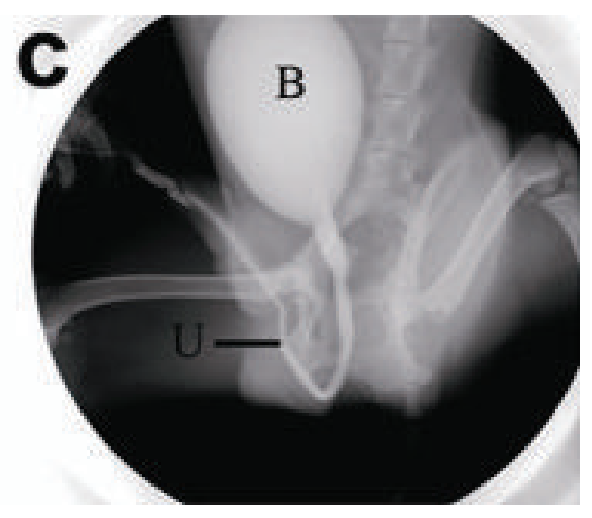

(c)

FIGURE 2: (a) The penis was with ruddy glans and mild pale penile skin, without swelling. (b) Normal urination of the transplanted penis. (c) Cystourethrography showing no urethrostenosis of the penis. Pa: penis allotransplant; B: bladder; U: urethra.

normal structures, without interstitial edema. The vessel walls were clear, with numerous red blood cells inside. Nerve bundles were found surrounding the blood vessels (Figures 3(a) and 3(b)).

All successfully transplanted penises $(n=12)$ survived under immunosuppressive treatment. Normal structure of the skin and mild swelling of the subcutaneous tissues were found. No embolism was found in the blood vessels. The structure of blood sinus in the cavernous body was normal, with limited infiltration of inflammatory cells. No interstitial degeneration or necrosis was found (Figures 4(a) and 4(b)).

Eight penises were excised because of pale color or signs of failure. Figure 5 presents the histopathological features of these penises, mainly including thrombosis, inflammatory cell infiltration, and tissue degradation.

\section{Discussion}

In two previous studies, penis transplantation was successfully performed in rat models $[21,22]$. However, the structure of the rat's penis is different from human's. Therefore, large animal models with penises more similar to humans' are needed. The blood flow of penis cavernous bodies of adult Beagles is mainly from the cavernosal arteries, although they also receive minor blood supply from the dorsal vessels [23], which is more similar to human's than rat models. In addition, animals should not be too expensive. Therefore, Beagle could be an appropriate large animal model for the investigation of penis transplantation. Indeed, previous studies have shown that adult Beagles could be used as models for the transplantation of a number of organs including lung, kidney, and heart transplantation for preclinical testing of drugs or as proof of concept [24-26]. The findings of the present study demonstrated that penile allotransplantation with microsurgical techniques was possible in Beagles in the same way as in previous studies of transplantation of other organs.

In the present study, 12 of the 20 transplanted penises survived well, suggesting that immunosuppressive agents could effectively suppress immunological rejection in penis transplantation. Eight penises were cut because they were pale in color or showed signs of failure, but not all of them were necessarily failures. Supportive treatments might have rescued some of them, but we were aiming at observing the morphological changes. These changes mainly included thrombosis, inflammatory cell infiltration, and tissue degradation, all of which are associated with organ failure/rejection $[27,28]$. In this study, the dorsal vessels were anastomosed, but it is likely that these failures might come from the inappropriate reconstitution of the blood supply from the external pudendal vessels. A recent study has shown that many penis transplants showed skin necrosis, probably for the same reason $[23,29]$. Indeed, Tuffaha et al. [23] underline that the dorsal arteries are necessary for distal penis perfusion, but that the external pudendal artery is necessary for adequate skin perfusion. On the other hand, the studies 


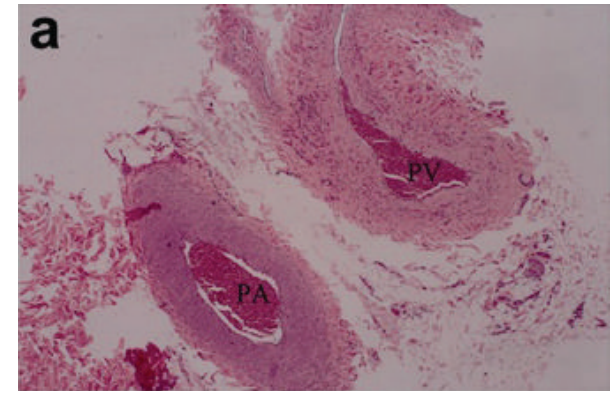

(a)

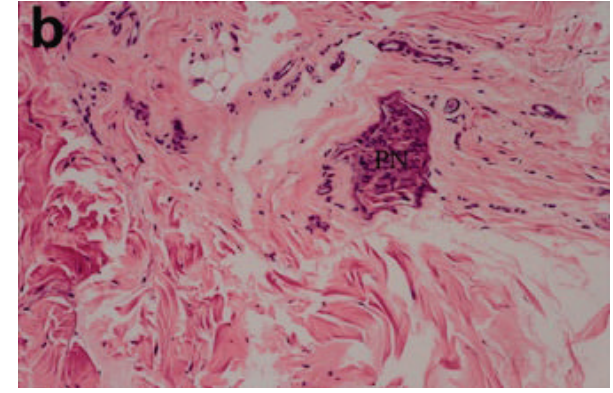

(b)

Figure 3: (a) Dorsal vein and artery of the penis in normal Beagles (magnification: 20x). (b) Penile nerve bundles in normal Beagles (magnification: 100x). PV: penis vein; PA: penis artery; PN: penis nerve.

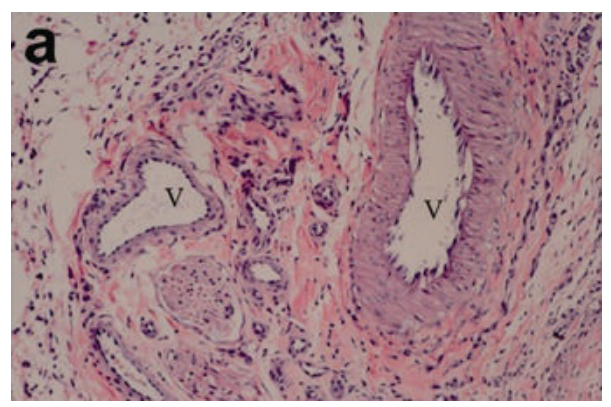

(a)

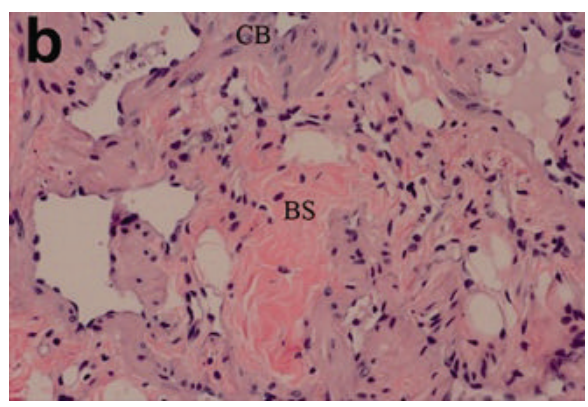

(b)

FIGURE 4: (a) No blood vessel embolism, and limited inflammatory cell infiltration (magnification: 100x). (b) Structure of the blood sinus in the cavernous body is normal, without degradation (magnification: 200x). V: vessels; CB: cavernous body; BS: blood sinus.

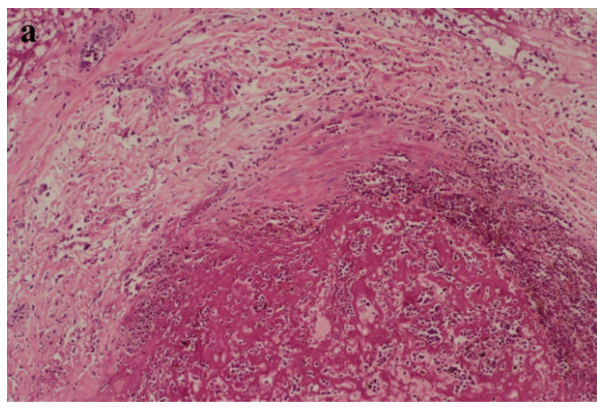

(a)

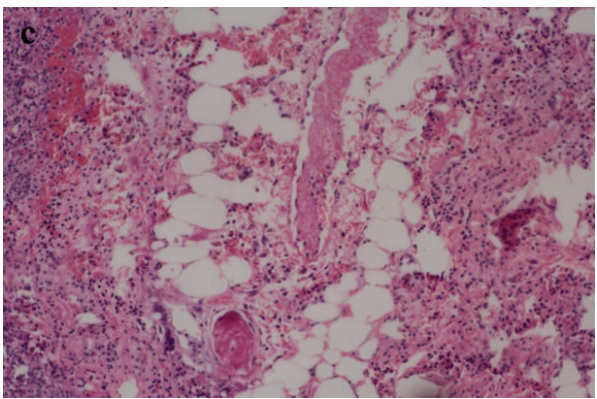

(c)

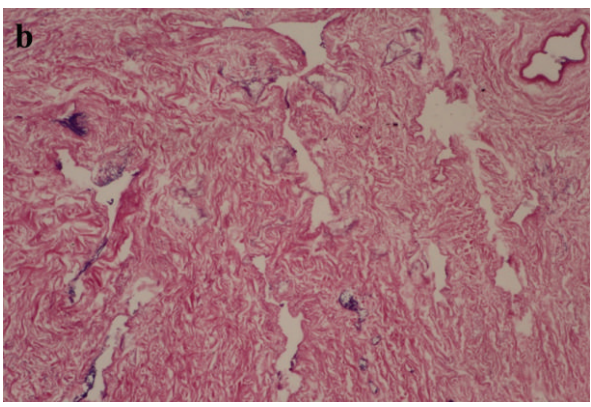

(b)

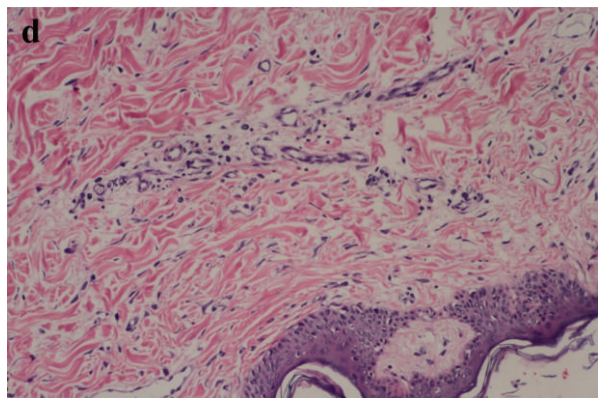

(d)

Figure 5: (a) Thrombosis in a vessel of a transplanted penis. Degradation can be seen in surrounding tissues $(\times 100)$. (b) Structure disorder in the corpus cavernosum. The blood sinus disappeared, leading to tissue degradation $(\times 100)$. (c) Inflammatory cell infiltration, vascular thrombosis, degradation, and edema in surrounding tissues $(\times 100)$. (d) Inflammatory cell infiltration of the subcutaneous tissue and degradation $(\times 100)$. 
by Tuffaha et al. [23, 29] were carried out using cadaveric penises, and it is unsure whether the anatomies are exactly the same between the human's and Beagle's penises. Additional studies are necessary to address this issue and to examine if skin necrosis could be avoided by external pudendal vessel anastomosis.

Previous studies on penis transplantation were performed in rats [21, 22], and no study was available in large animals. Therefore, we based our immunosuppressive regimen on these studies in rats and on our experience. Results showed that this regimen seemed adequate. However, future studies should be performed to address the most appropriate and optimal immunosuppressive regimen. Recent strategies in kidney transplantation have been shown to be efficient for composite tissue allograft and might be used for penis allotransplantation [30]. In a previous study performed by Koga et al., the survival rate of the transplanted penises was $100 \%$ after FK506 treatment, and rejection was minimal to moderate on Days 3 and 5 after transplantation and minimal or absent on Days 7, 10, 14, and 21 [13].

In 2006, our center reported a case of penile allotransplantation in a trauma patient. In that case, the deep dorsal vein, dorsal artery, and accompanying nerves were successfully anastomosed with microsurgical techniques, the cavernous body of the urethra and albuginea of the cavernous body was sutured, and a $16 \mathrm{~F}$ double-channel catheter was implanted. Maintenance immunosuppressive treatment with combined use of cyclosporine A, mycophenolate mofetil, and prednisone was performed after surgery. The blood supply of the transplanted penis was adequate, and the catheter was removed on day 10 . No rejection reaction or infection was found, and the patient could urinate normally. However, despite technical success, the penis was resected on Day 14 due to the psychological repellence of the patient and his family [12]. This repellence could not be predicted, but psychological counseling might have prevented it. This will be an issue to address in eventual clinical trials. Nevertheless, it could be noted by its color that the skin of the penis was maybe suffering from an inadequate blood supply, which might be due to improper anastomosis of the external pudendal arteries [23, 29]. Again, as for the Beagles, additional studies are necessary to address this issue.

The advancement of several technologies including transplantation immunity, tissue typing and immunosuppressants, the high long-term survival rate of extremity allotransplantation in animals, and the high success rate of penis allotransplantation in the present study provides a solid ground for treating patients with penile defect using penis transplantation. Penis defects do not endanger the life of the patients but cause profound psychological problems that greatly affect the patients' quality of life. Therefore, we believe that if using a proper immunosuppressive regimen, penis transplantation could be ethical in selected cases. In a similar manner, disfigurement does not endanger life, but a recent bioethics analysis has shown that there are valid arguments for facial transplantation despite the risks associated with the procedure [31]. Similar arguments could be applied to penis transplantation. Erectile function was not assessed in the present study but will be in a future study.

\section{Conclusion}

The present study strongly suggests that the structure of the penis cavernous body is highly similar in Beagles compared with humans. Therefore, penis allotransplantation could be successfully performed with microsurgical techniques. Adult Beagles could be used as an experimental model for the investigation of penis allotransplantation.

\section{Conflict of Interests}

The authors declare that there is no conflict of interests regarding the publication of this paper.

\section{Authors' Contribution}

Yongbin Zhao and Weilie $\mathrm{Hu}$ contributed equally to this study.

\section{References}

[1] N. Mertziotis, D. Kozyrakis, and E. Bogris, "Is V-Y plasty necessary for penile lengthening? Girth enhancement and increased length solely through circumcision: description of a novel technique," Asian Journal of Andrology, vol. 15, no. 6, pp. 819-823, 2013.

[2] I. Ludolph, T. Titel, J. P. Beier et al., "Penile reconstruction with dermal template and vacuum therapy in severe skin and soft tissue defects caused by Fournier's gangrene and hidradenitis suppurativa," International Wound Journal, vol. 13, no. 1, pp. 7781, 2016.

[3] M. Rashid and M. S. Tamimy, "Phalloplasty: the dream and the reality," Indian Journal of Plastic Surgery, vol. 46, no. 2, pp. 283293, 2013.

[4] M. Tuerk and W. H. Weir Jr., "Successful replantation of a traumatically amputated glans penis. Case report," Plastic and Reconstructive Surgery, vol. 48, no. 5, pp. 499-500, 1971.

[5] F. Colombo and A. Casarico, "Penile enlargement," Current Opinion in Urology, vol. 18, no. 6, pp. 583-588, 2008.

[6] B. E. Dillon, N. B. Chama, and S. C. Honig, "Penile size and penile enlargement surgery: a review," International Journal of Impotence Research, vol. 20, no. 6, pp. 519-529, 2008.

[7] S. Phonsombat, V. A. Master, and J. W. McAninch, "Penetrating external genital trauma: a 30-year single institution experience," The Journal of Urology, vol. 180, no. 1, pp. 192-196, 2008.

[8] E.-K. Chou, Y.-T. Tai, C.-I. Wu, M.-S. Lin, H.-H. Chen, and S. C.-N. Chang, "Penile replantation, complication management, and technique refinement," Microsurgery, vol. 28, no. 3, pp. 153156, 2008.

[9] B. V. Srinivas, S. S. Vasan, and S. Mohammed, "Penile lengthening procedure with V-Y advancement flap and an interposing silicone sheath: a novel methodology," Indian Journal of Urology, vol. 28, no. 3, pp. 340-342, 2012.

[10] O. K. Z. Shaeer, K. Shaeer, and A. El-Sebaie, "Minimizing the losses in penile lengthening: 'V-Y half-skin half-fat advancement flap' and 'T-closure' combined with severing the suspensory ligament," Journal of Sexual Medicine, vol. 3, no. 1, pp. 155$160,2006$.

[11] S. Lee, L. Mao, Y. Wang et al., "Transplantation of reproductive organs," Microsurgery, vol. 16, no. 4, pp. 191-198, 1995. 
[12] W. Hu, J. Lu, L. Zhang et al., "A preliminary report of penile transplantation," European Urology, vol. 50, no. 4, pp. 851-853, 2006.

[13] H. Koga, A. Yamataka, K. Wang et al., "Experimental allogenic penile transplantation," Journal of Pediatric Surgery, vol. 38, no. 12, pp. 1802-1805, 2003.

[14] R. Llull, "An open proposal for clinical composite tissue allotransplantation," Transplantation Proceedings, vol. 30, no. 6, pp. 2692-2703, 1998.

[15] W. P. Cooney and V. R. Hentz, "Hand transplantation-primum non nocere," Journal of Hand Surgery, vol. 27, no. 1, pp. 165-168, 2002.

[16] A. Rahmel, "Vascularized composite allografts: procurement, allocation, and implementation," Current Transplantation Reports, vol. 1, no. 3, pp. 173-182, 2014.

[17] L. Galek, B. Darewicz, J. Kudelski, T. Werel, and J. Darewicz, "Microsurgical replantation of sexual organs in three patients," Scandinavian Journal of Urology and Nephrology, vol. 36, no. 1, pp. 14-17, 2002.

[18] M. Mayrink and P. R. da Costa, "Successful primary microsurgical replantation of an avulsed penis," Plastic and Reconstructive Surgery, vol. 109, no. 3, pp. 1202-1203, 2002.

[19] Y.-L. Sa, Y.-M. Xu, Z.-S. Liu, C. Feng, and X.-F. Fei, "Pedicled rectus abdominis muscle flap wrapped around the penis for enhanced urethral pressure: an experimental study in dogs," Urologia Internationalis, vol. 78, no. 1, pp. 42-45, 2007.

[20] K. K. Mittal, M. R. Mickey, D. P. Singal, and P. I. Terasaki, "Serotyping for homotransplantation. 18. Refinement of microdroplet lymphocyte cytotoxicity test," Transplantation, vol. 6, no. 8, pp. 913-927, 1968.

[21] R. M. Seyam, S. A. Kattan, L. W. Assad, R. M. El-Sayed, and F. H. Almohanna, "Penile autotransplantation in rats: an animal model," Urology Annals, vol. 5, no. 4, pp. 255-258, 2013.

[22] E. Sonmez, S. Nasir, and M. Siemionow, "Penis allotransplantation model in the rat," Annals of Plastic Surgery, vol. 62, no. 3, pp. 304-310, 2009.

[23] S. H. Tuffaha, J. M. Sacks, J. T. Shores et al., "Using the dorsal, cavernosal, and external pudendal arteries for penile transplantation: technical considerations and perfusion territories," Plastic and reconstructive surgery, vol. 134, no. 1, pp. 11le-119e, 2014.

[24] M. Kamler, K. Nowak, M. Bock et al., "Bronchial artery revascularization restores peribronchial tissue oxygenation after lung transplantation," Journal of Heart and Lung Transplantation, vol. 23, no. 6, pp. 763-766, 2004.

[25] F. Kinugasa, I. Nagatomi, T. Nakanishi et al., "Effect of the immunosuppressant histone deacetylase inhibitor FR276457 in a canine renal transplant model," Transplant Immunology, vol. 21, no. 4, pp. 198-202, 2009.

[26] M. Ueno, Y. Moriyama, R. Toda et al., "Effect of a neutrophil elastase inhibitor (ONO-5046 Na) on ischemia/reperfusion injury using the left-sided heterotopic canine heart transplantation model," Journal of Heart and Lung Transplantation, vol. 20, no. 8, pp. 889-896, 2001.

[27] P. S. Randhawa, R. Shapiro, M. L. Jordan, T. E. Starzl, and A. J. Demetris, "The histopathological changes associated with allograft rejection and drug toxicity in renal transplant recipients maintained on FK506. Clinical significance and comparison with cyclosporine," The American Journal of Surgical Pathology, vol. 17, no. 1, pp. 60-68, 1993.
[28] J. M. Vierling and R. H. Fennell Jr., "Histopathology of early and late human hepatic allograft rejection: evidence of progressive destruction of interlobular bile ducts," Hepatology, vol. 5, no. 6, pp. 1076-1082, 1985.

[29] S. H. Tuffaha, J. D. Budihardjo, K. A. Sarhane, S. C. Azoury, and R. J. Redett, "Expect skin necrosis following penile replantation," Plastic \& Reconstructive Surgery, vol. 134, no. 6, pp. 1000e1004e, 2014.

[30] J. Chang, C. L. Davis, and D. W. Mathes, “The impact of current immunosuppression strategies in renal transplantation on the field of reconstructive transplantation," Journal of Reconstructive Microsurgery, vol. 28, no. 1, pp. 7-19, 2012.

[31] L. K. Kalliainen, "Supporting facial transplantation with the pillars of bioethics," Journal of Reconstructive Microsurgery, vol. 26, no. 8, pp. 547-553, 2010. 


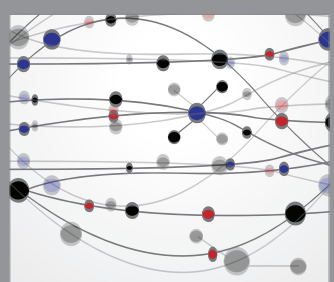

The Scientific World Journal
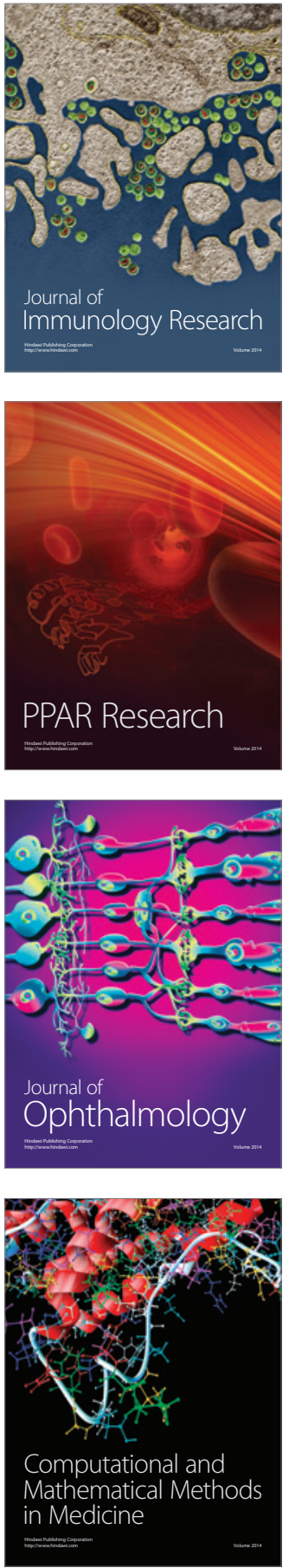

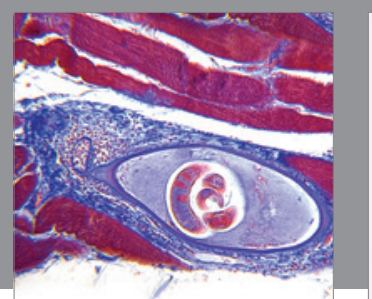

Gastroenterology Research and Practice

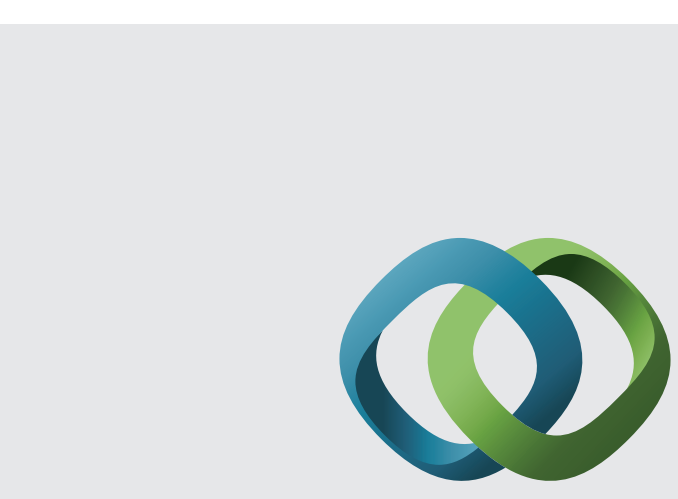

\section{Hindawi}

Submit your manuscripts at

http://www.hindawi.com
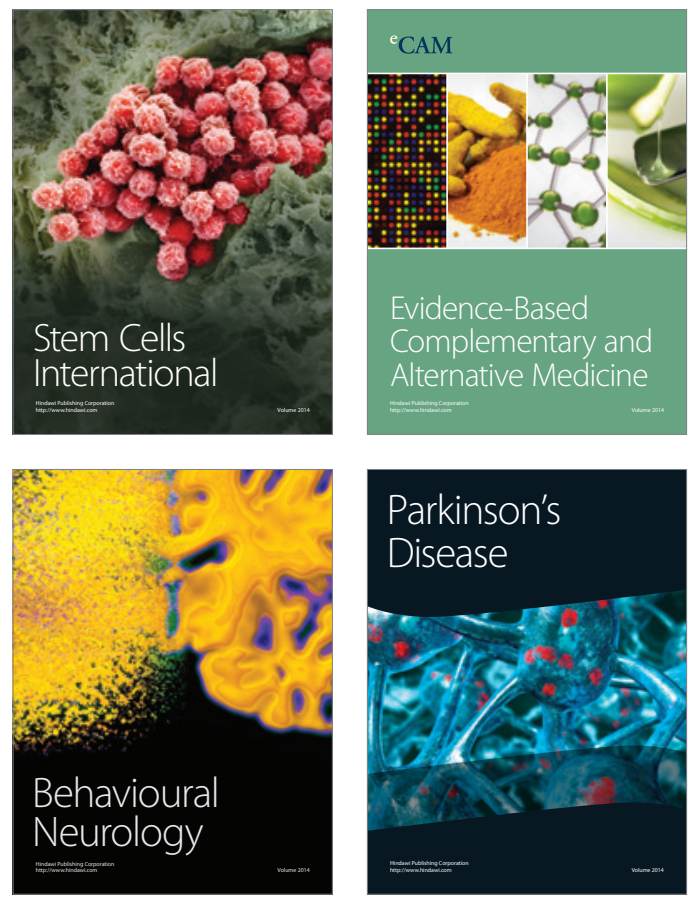
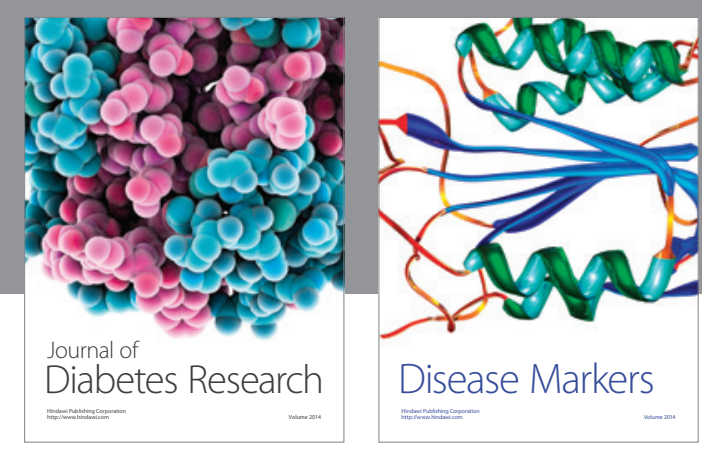

Disease Markers
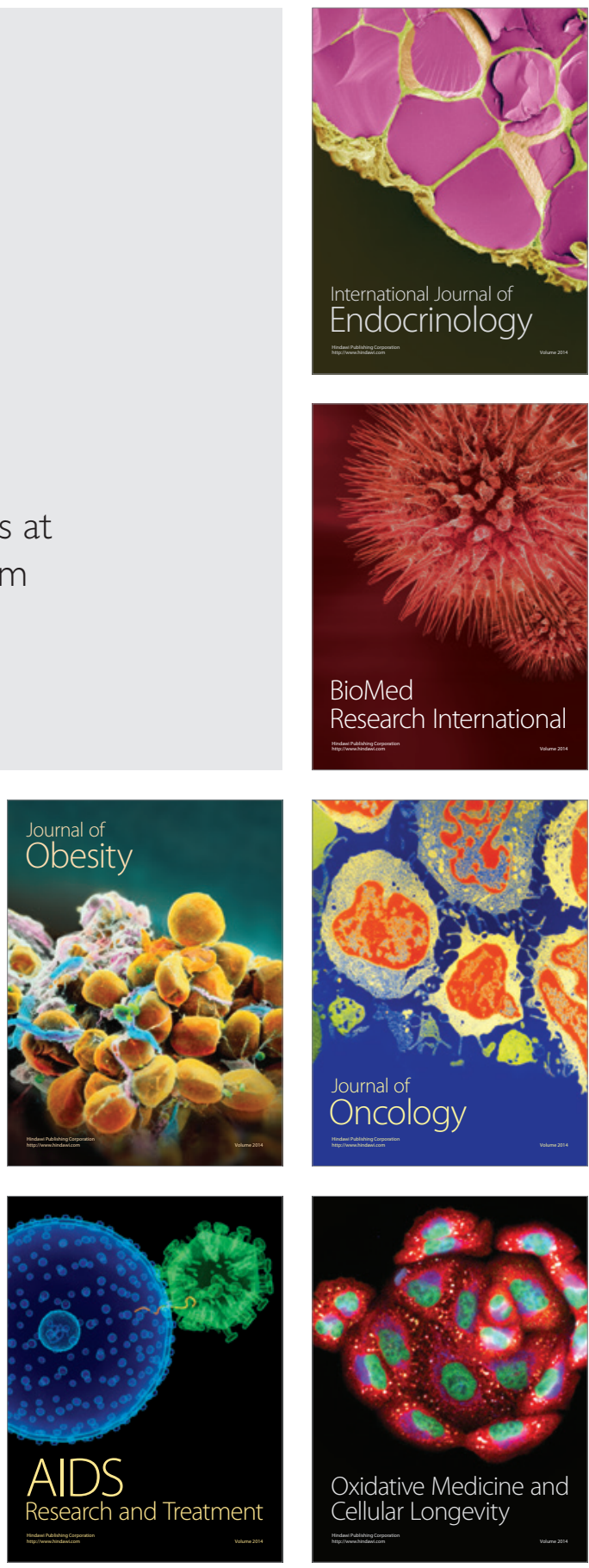